OPEN ACCESS

Edited by:

Liang Wu,

Chongqing University, China

Reviewed by:

You Zhang,

Beijing Institute of Petrochemical

Technology, China

Zhihui Xie,

China West Normal University, China

${ }^{*}$ Correspondence:

Yun Zhao

yun_zhaotju@163.com

Minfang Chen

mfchentj@126.com

tThese authors have contributed equally to this work

Specialty section: This article was submitted to

Structural Materials,

a section of the journal

Frontiers in Materials

Received: 22 October 2021 Accepted: 25 November 2021

Published: 27 January 2022

Citation:

$L i T$, Chen G, Xiang M, Zhao Y and Chen $M$ (2022) Effect of $\mathrm{ZrSiO}_{4}$ Concentration on the Microstructure and Corrosion Resistance of MAO

Coatings Formed on AZ91

Magnesium Alloy.

Front. Mater. 8:799780.

doi: 10.3389/fmats.2021.799780

\section{Effect of $\mathrm{ZrSiO}_{4}$ Concentration on the Microstructure and Corrosion Resistance of MAO Coatings Formed on AZ91 Magnesium Alloy}

\author{
Tianlu $\mathrm{Li}^{1 \dagger}$, Guorui Chen ${ }^{1 \dagger}$, Mingzhe Xiang ${ }^{1}$, Yun Zhao ${ }^{1,2,3 *}$ and Minfang Chen ${ }^{1,2,3 *}$ \\ ${ }^{1}$ School of Materials Science and Engineering, Tianjin University of Technology, Tianjin, China, ${ }^{2}$ Key Laboratory of Display \\ Materials and Photoelectric Device (Ministry of Education), Tianjin University of Technology, Tianjin, China, ${ }^{3} \mathrm{National}$ \\ Demonstration Center for Experimental Function Materials Education, Tianjin University of Technology, Tianjin, China
}

As a metallic material with lightweight and high specific strength, magnesium alloy has excellent application prospects. However, the rapid corrosion rate and localized corrosion behavior of magnesium alloys limit the practical application in the automobile industry. In this study, to improve the corrosion resistance of AZ91 alloy, the film of different concentrations containing zirconium (AZR0, AZR5, AZR10, AZR15) was prepared on the surface of $A Z 91$ alloy by micro-arc oxidation technology in the $\mathrm{Na}_{2} \mathrm{SiO}_{3}-\mathrm{Na}_{3} \mathrm{PO}_{4}$ system. Furthermore, the influence of electrolyte composition on the corrosion resistance of the MAO film was systematically investigated. The experimental results revealed that the $\mathrm{ZrSiO}_{4}$ particles added in the electrolyte could enter into the MAO film and $\mathrm{ZrSiO}_{4}$ particles were also decomposed into $\mathrm{ZrO}_{2}$ and $\mathrm{Mg}_{2} \mathrm{Zr}_{5} \mathrm{O}_{11}$ in the process of micro-arc oxidation. More importantly, the formation of micro-cracks and other defects in the film could be reduced after this process. The addition of $15 \mathrm{gl}^{-1} \mathrm{ZrSiO}_{4}$ in the electrolyte was contributed to the best comprehensive properties of MAO-processed AZ91 specimens, including improved Vickers hardness of $167.16 \mathrm{Hv}$, Young's modulus of $652 \mathrm{MPa}$, and enhanced corrosion resistance $\left(R_{P}=9.82 \times 10^{5} \Omega \mathrm{cm}^{2}\right)$. This approach could provide the approach for developing $\mathrm{Mg}$-based materials with high anticorrosion in industrial fields.

Keywords: magnesium alloy, micro-arc oxidation (MAO), $\mathrm{ZrSiO}_{4}$, anti-corrosion, microstructure

\section{INTRODUCTION}

Magnesium-based (Mg-based) material has been recognized as a promising alternative to conventional Al-based load-bearing materials due to its high strength-to-weight ratio and low density (Zhang et al., 2019). The considerable drawback of magnesium and its alloys is that they are impressionable to corrosion in a high-humidity atmosphere, which seriously restricts their industrial applications (Li et al., 2020a).

Defense of $\mathrm{Mg}$ in anti-corrosion can usually be acquired by three strategies: alloying, composite formation, and protective coatings. Generally, surface modification can observably improve the corrosion resistance of substrate without influencing its initial properties (Li et al., 2020b). Surface treatment techniques, including anodic oxidation (Zarei et al., 2021), plasma spraying (Cao et al., 2021), vapor deposition (Li et al., 2021), sol-gel film (Zhang et al., 2021), and micro-arc oxidation 
(Zhang et al., 2020a), were widely used for this purpose. Among the techniques as mentioned above, micro-arc oxidation (MAO) technology can contribute to a protective oxide layer on the surface of metallic materials in instantaneous high temperature and high pressure by generating spark discharges. Because of the feature of MAO, the oxide layer is formed on the substrate, resulting in strong interfacial bonding between the metallic substrate and MAO coating ( $\mathrm{Lu}$ et al., 2016). Thus, the MAO process is extensively used to improve the corrosion resistance of Mg-based materials. Several previous studies have revealed that the electrolyte composition is essential and crucial to improving the comprehensive performance of MAO coating, like corrosion resistance and adhesion strength, and control the corrosion behavior of Mg-relevant materials (Fattah-alhosseini et al., 2020).

Researchers have added miscellaneous micro/nano irresolvable particles into the electrolytes, which can participate in the MAO process and form into parts of the coatings. Generally, this in-situ technology for preparing composite coating deposits ceramic particles, such as $\mathrm{SiC}$ (Wang et al., 2015) and $\mathrm{CeO}_{2}$ (Lim et al., 2012). For example, MAO coating incorporated with $\mathrm{CeO}_{2}$ was obtained on AZ91D $\mathrm{Mg}$ alloy. The EIS and potentiodynamic tests in $3.5 \mathrm{wt} \% \mathrm{NaCl}$ solution indicated that the anticorrosion behavior of MAOprocessed AZ31 Mg alloy was markedly improved (Lim et al., 2012).

Zirconium is a potential biomaterial for dental and orthopedic implants owing to its high mechanical strength, high corrosion resistance, and excellent biocompatibility. $\mathrm{ZrO}_{2}$ has the strengths of high mechanical strength, strong toughness, and good corrosion resistance. In addition, $\mathrm{ZrO}_{2}$ influences stress-induced transformation toughening (Zhou et al., 2021).

Therefore, in some studies, $\mathrm{K}_{2} \mathrm{ZrF}_{6^{-}}$and $\mathrm{ZrO}_{2}$-doped composite MAO coatings were prepared. For example, Arrable et al. (Arrabal et al., 2008) showed the allocation of $\mathrm{ZrO}_{2}$ nanoparticles across the surface and cross section of the coating. Li et al. ( $\mathrm{Li}$ et al., 2015) reported enrichment in the
TABLE 1 | Composition of electrolyte.

\begin{tabular}{lcccc}
\hline \multirow{2}{*}{ Samples } & \multicolumn{4}{c}{ Concertation of electrolytes } \\
\cline { 2 - 5 } & $\mathbf{N a O H}$ & $\mathbf{N a}_{\mathbf{3}} \mathbf{P O}_{\mathbf{4}} \cdot \mathbf{9} \mathbf{H}_{\mathbf{2}} \mathbf{O}$ & $\mathbf{N a}_{\mathbf{2}} \mathbf{S i O}_{\mathbf{3}} \cdot \mathbf{1 2} \mathbf{H}_{\mathbf{2}} \mathbf{O}$ & $\mathbf{Z r S i O}_{\mathbf{4}}$ \\
\hline AZR0 & $6 \mathrm{~g} / \mathrm{l}$ & $9.3 \mathrm{~g} / \mathrm{l}$ & $2.3 \mathrm{~g} / \mathrm{l}$ & $0 \mathrm{~g} / \mathrm{l}$ \\
AZR5 & $6 \mathrm{~g} / \mathrm{l}$ & $9.3 \mathrm{~g} / \mathrm{l}$ & $2.3 \mathrm{~g} / \mathrm{l}$ & $5 \mathrm{~g} / \mathrm{l}$ \\
AZR10 & $6 \mathrm{~g} / \mathrm{l}$ & $9.3 \mathrm{~g} / \mathrm{l}$ & $2.3 \mathrm{~g} / \mathrm{l}$ & $10 \mathrm{~g} / \mathrm{l}$ \\
AZR15 & $6 \mathrm{~g} / \mathrm{l}$ & $9.3 \mathrm{~g} / \mathrm{l}$ & $2.3 \mathrm{~g} / \mathrm{l}$ & $15 \mathrm{~g} / \mathrm{l}$
\end{tabular}

anticorrosion of the $\mathrm{ZrO}_{2}$-containing $\mathrm{MAO}$ coatings on $\mathrm{TC} 4$ alloy. Zhang et al. (Zhang et al., 2010) used $\mathrm{K}_{2} \mathrm{ZrF}_{6}$-based electrolyte and acquired MAO coatings consisting of the $\mathrm{ZrO}_{2}$ phase. Koo et al. (Rehman et al., 2017) studied the MAO coatings manufactured on AZ31B $\mathrm{Mg}$ alloy in $\mathrm{K}_{2} \mathrm{ZrF}_{6}-\mathrm{Na}_{2} \mathrm{SiO}_{3}$-based electrolyte. It was observed that the hardness and anticorrosion properties of the coatings were highly improved after MAO processing.

Zircon $\left(\mathrm{ZrSiO}_{4}\right)$, as a common and cheap particle for industrial use, has excellent physical and chemical capabilities, such as good mechanical properties, reducing friction coefficient, and enhancing corrosion resistance (Yang et al., 2021). However, the participant investigation in the literature has been rarely recorded, showing that $\mathrm{ZrO}_{2}$ ceramic coating can be provided with MAO technology. Therefore, in this work, MAO of AZ91 $\mathrm{Mg}$ alloy was conducted in $\mathrm{ZrSiO}_{4}$-containing $\mathrm{Na}_{2} \mathrm{SiO}_{3}-\mathrm{Na}_{3} \mathrm{PO}_{4}$ based electrolyte, and electrochemical corrosion properties of $\mathrm{ZrSiO}_{4}$ particle-containing MAO coatings on AZ91 Mg alloy were evaluated by the potentiodynamic test.

\section{MATERIALS AND METHODS}

\section{Materials}

The substrate used in this work was a commercial material, AZ91 $\mathrm{Mg}$ alloy (wt\%:0.35 Zn, 0.15 Mn, 8.3 Al, Mg Bal.). For the MAO process, the extruded bar samples of AZ91 Mg alloy were cut into
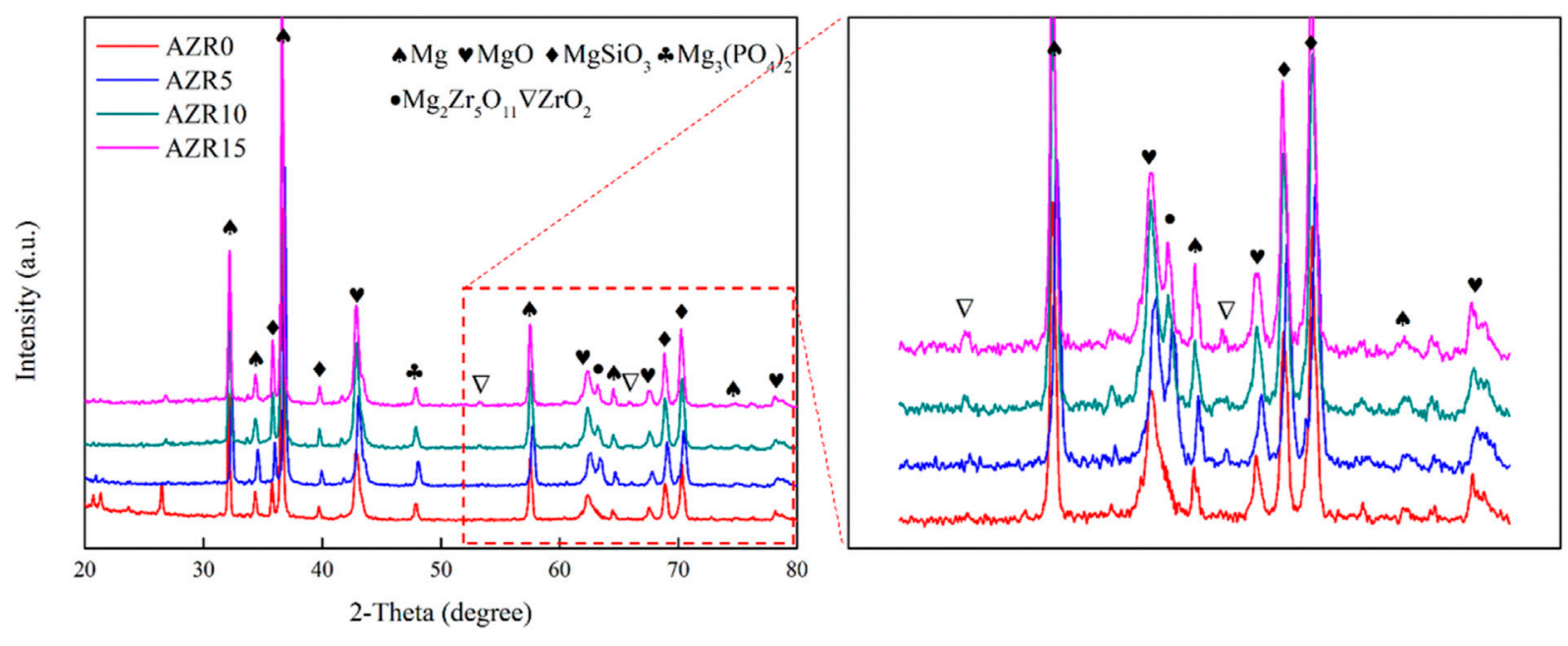

FIGURE 1 | The XRD patterns of the samples. 


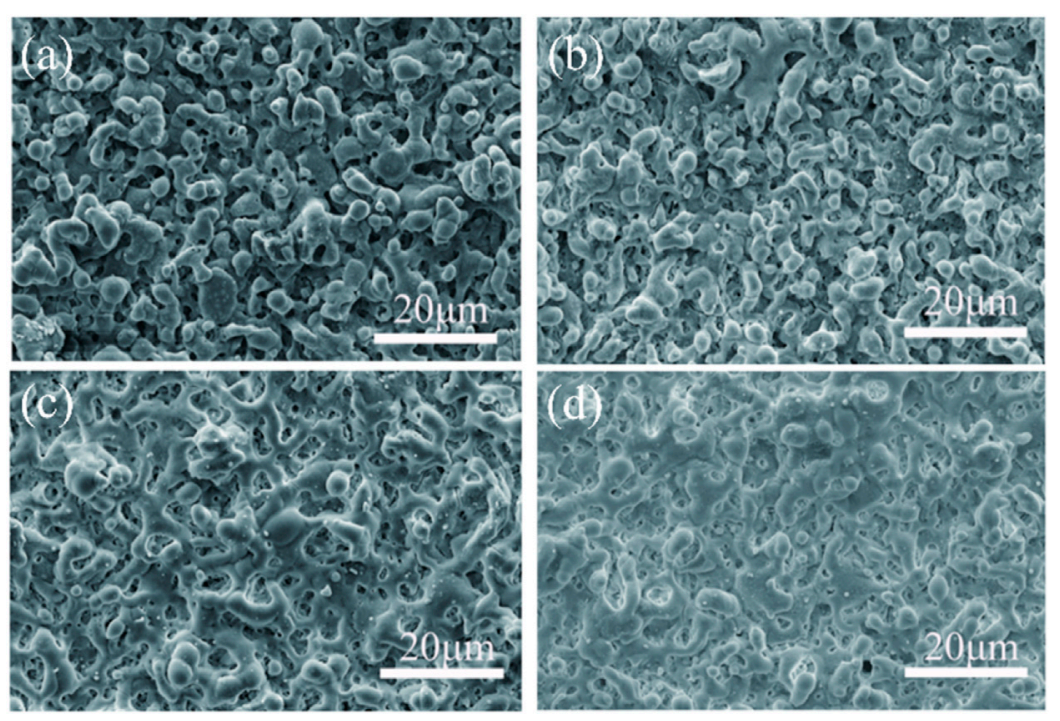

FIGURE 2 | SEM morphologies of the different samples (A) AZR0, (B) AZR5, (C) AZR10, and (D) AZR15.
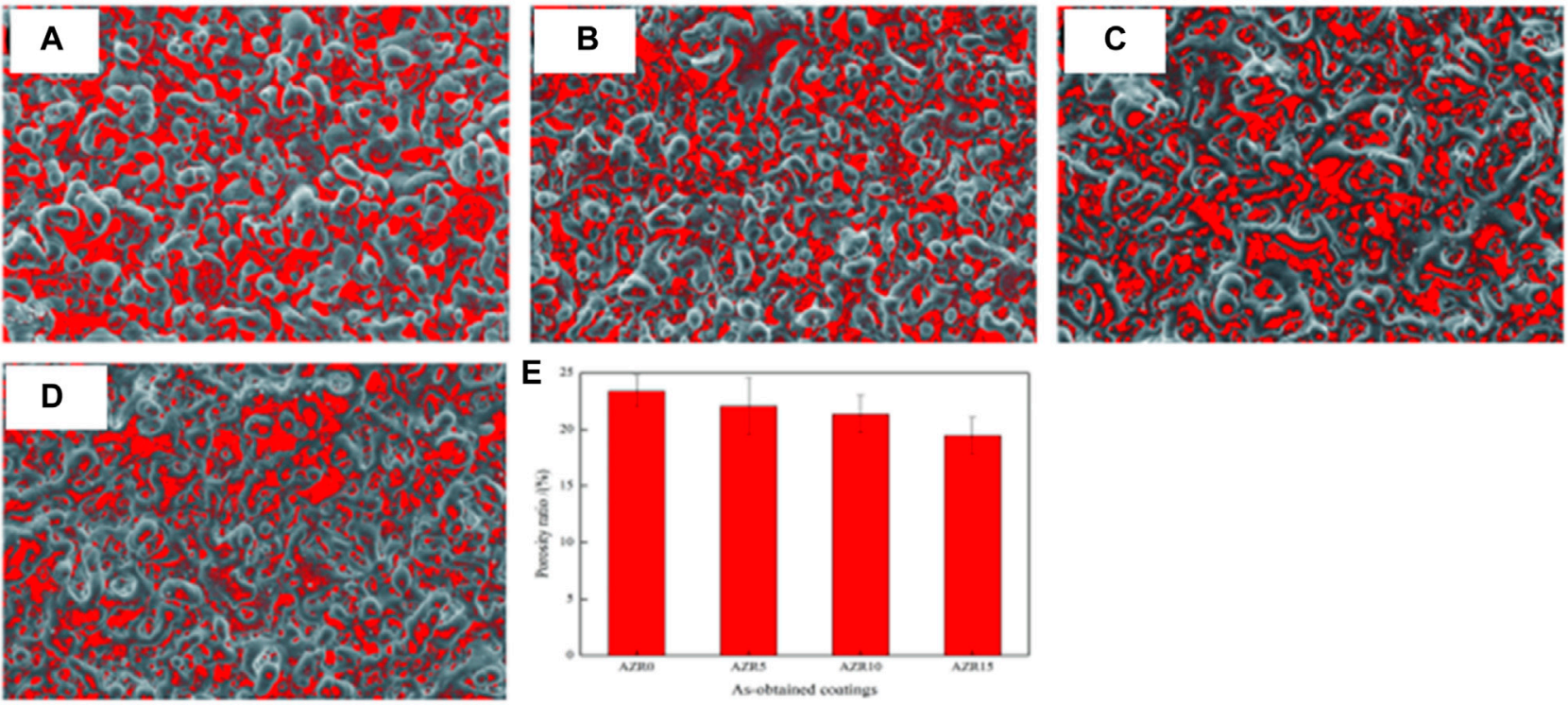

FIGURE 3 | Porosity ratio of the different samples (A) AZR0, (B) AZR5, (C) AZR10, and (D) AZR15.

TABLE 2 | Elemental compositions of different samples analyzed by EDS.

\begin{tabular}{lccccc}
\hline \multirow{2}{*}{ Samples } & \multicolumn{5}{c}{ Element (Weight \%) } \\
\cline { 2 - 6 } & $\mathbf{O}$ & $\mathbf{M g}$ & $\mathbf{S i}$ & $\mathbf{P}$ & $\mathbf{Z r}$ \\
\hline AZR0 & 42.71 & 49.80 & 3.11 & 4.38 & -- \\
AZR5 & 39.78 & 47.64 & 3.96 & 1.49 & 7.11 \\
AZR10 & 38.45 & 42.62 & 4.90 & 0.76 & 13.27 \\
AZR15 & 38.72 & 36.12 & 5.72 & 1.44 & 18.00
\end{tabular}

a shape $\Phi 8 \mathrm{~mm} \times 3 \mathrm{~mm}$. The samples were then ground by $\mathrm{SiC}$ sandpaper up to 2000\#, washed with ethanol in ultrasound for $10 \mathrm{~min}$, and dried in air.

\section{Preparation of MAO Coating}

The MAO coatings were accomplished utilizing an installation consisting of an MAO-50D power supply. Mg alloy AZ91 was regarded as the anode, and stainless steel was used as the cathode. The mode of MAO was constant pressure. The termination 

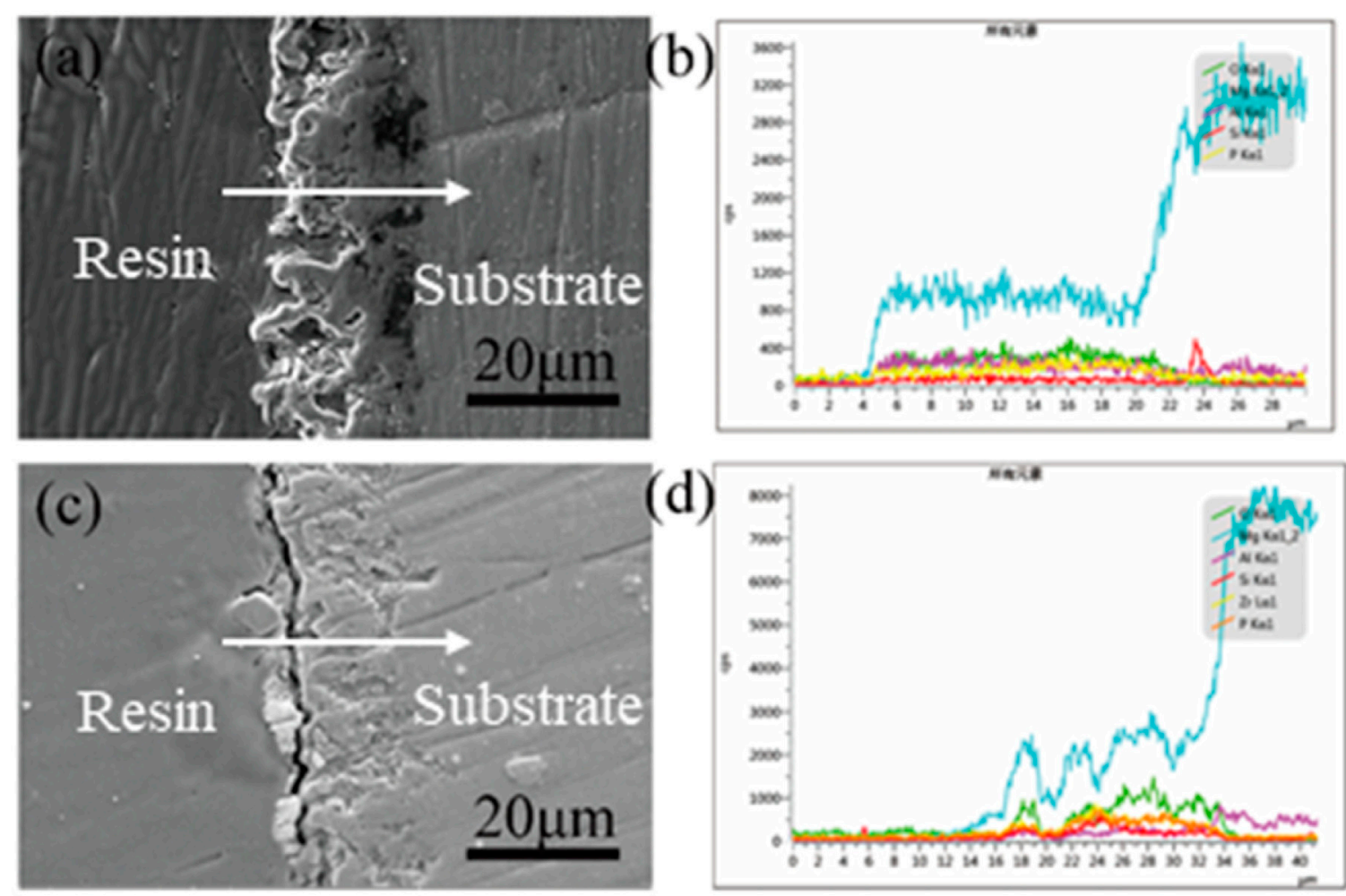

(d)
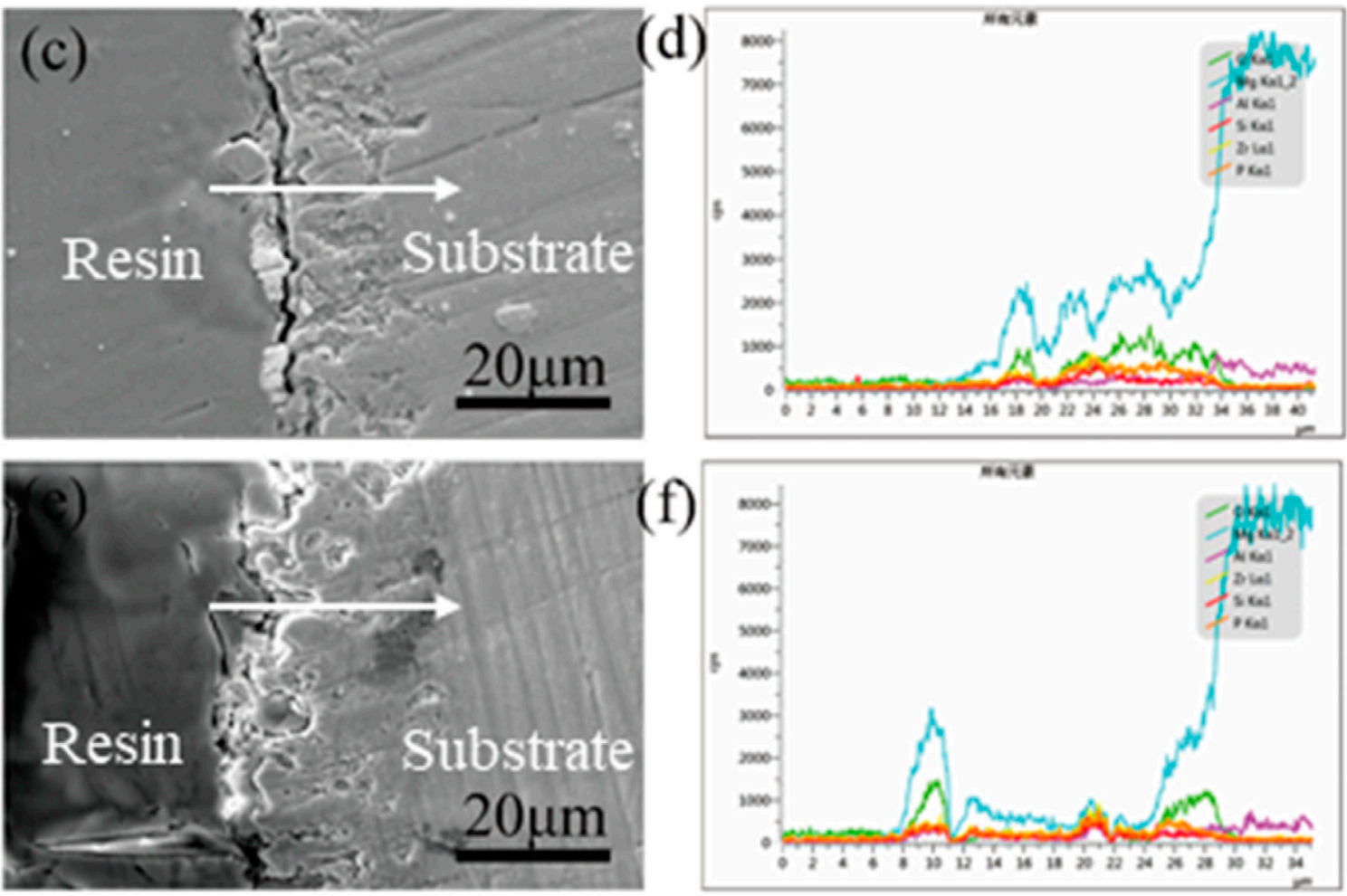

(f)
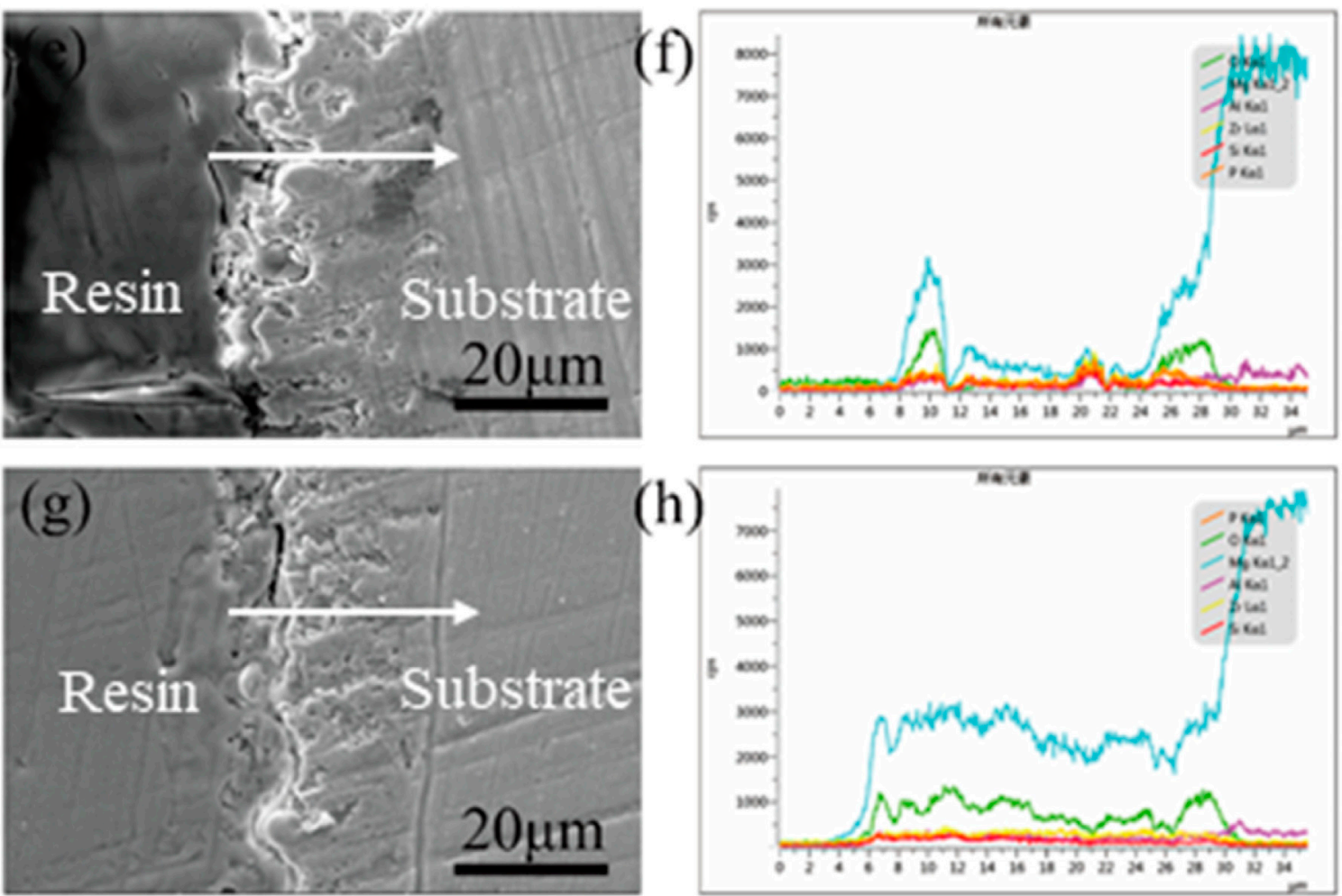

(h)

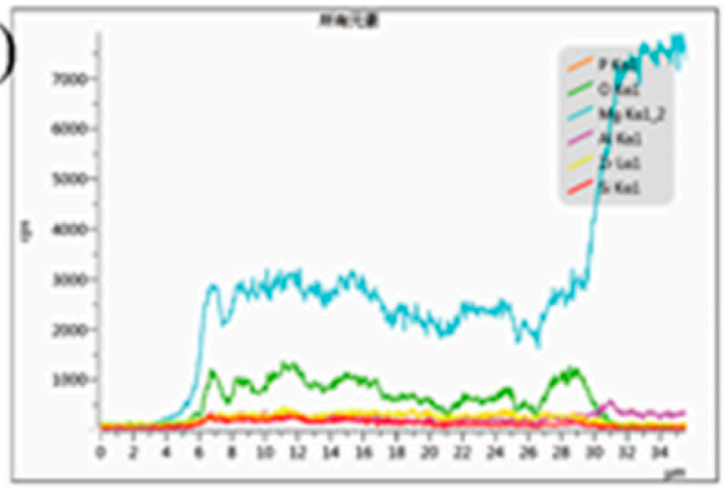

FIGURE 4 | SEM morphologies and EDS results of the cross-sectional views of the different samples (A) AZRO, (B) AZR5, (C) AZR10, and (D) AZR15. 


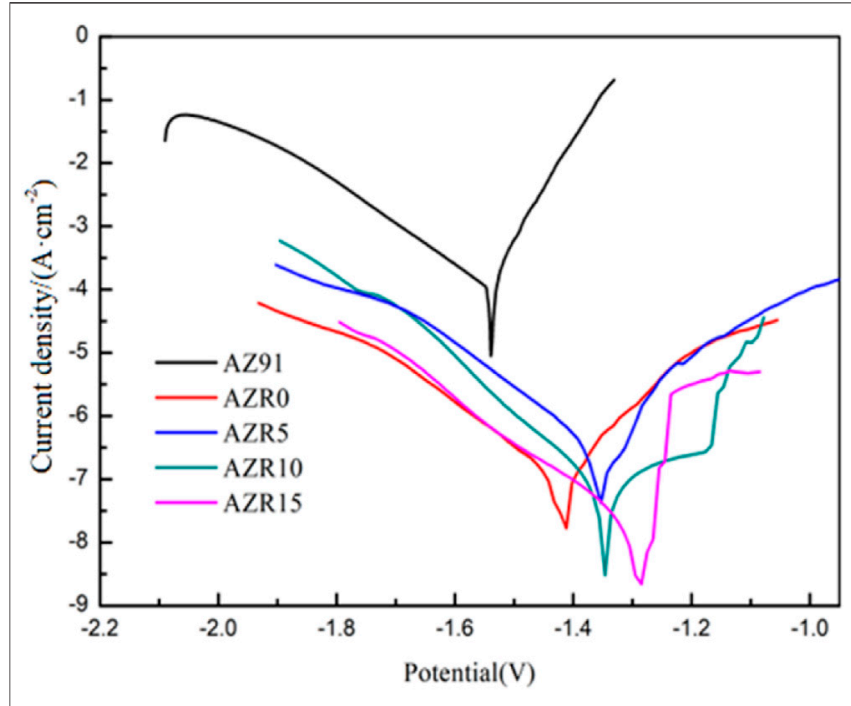

FIGURE 5 | Potentiometric polarization curves of the different samples.

voltage, frequency, duty cycle, and oxidation time were fixed at $400 \mathrm{~V}, 600 \mathrm{~Hz}, 30 \%$, and $10 \mathrm{~min}$, respectively. The electrolytes used in the MAO process are shown in Table 1. The average size of $\mathrm{ZrSiO}_{4}$ powder particles in the electrolyte was approximately $737.5 \mathrm{~nm}$, and sodium dodecylbenzene sulfonate was added as an anionic surfactant to ensure the particles evenly dispersed in the solution.

\section{Characterization}

The phase constituents of obtained samples were analyzed using an X-ray diffractometer (XRD, D/max-2500). The surface and cross-section morphology were investigated using a field emission scanning electron microscope (SEM, Quanta FEG250). Moreover, elemental compositions of surface and cross section were observed using a SEM-attached energy dispersive X-ray spectrometry (EDS) device. Sample wettability was characterized via a static contact angle goniometer (DSA1000, Kruss, Germany) using deionized water droplets (volume of one drop $=3 \mu \mathrm{l})$. Three different positions were chosen to be measured for each sample. The porosity ratio in the coating surface was analyzed using ImageJ software.

The corrosion behavior was gauged using a Zennium electrochemical workstation after the open circuit potential (OCP) for $30 \mathrm{~min}$ to be stabilized in a $3.5 \% \mathrm{NaCl}$ solution. A representative three-electrode mechanism was composed of graphite electrode as an auxiliary electrode, saturated calomel electrode (SCE) as a reference electrode, and specimen $\left(1 \mathrm{~cm}^{2}\right.$ exposed area) as a working electrode. The corrosion resistance was employed to study the Tafel curve to give the corrosion potential $\left(E_{c o r r}\right)$, the corrosion current density $\left(I_{\text {corr }}\right)$, the slope of cathodic polarization $\left(\beta_{c}\right)$, and the slope of the anodic polarization branch $\left(\beta_{a}\right)$. In addition, the polarization resistance, $R_{p}$, and inverse ratio to corrosion rate can be computed using the simplified Stern-Geary Equation 1 (Li et al., 2020c). Eq. 2 was converted to the protection efficiency (Rahman et al., 2020).

$$
\begin{gathered}
R p=\frac{\beta a \times \beta c}{2.303 \times I_{\text {corr }}(\beta a+\beta c)} \\
E_{\text {protection }}=1-\frac{I_{(\text {corr }) c}}{I_{(\text {corr }) u c}}
\end{gathered}
$$

$I\left(c_{c o r r}\right)_{u c}$ is the corrosion current density of substrate AZ91 Mg alloy, and $I\left({ }_{\text {corr }}\right)_{c}$ is the corrosion current density after the MAO process on AZ91 Mg alloy.

A binding force tester (WS-2005) was utilized for testing the adhesion strength of samples. The adhesion strength of the film was calculated using the formula shown by Equation 3. The dynamic load was $40 \mathrm{~N}$, the loading time was $1 \mathrm{~min}$, and the scratch length was $3 \mathrm{~mm}$.

$$
P=\frac{F}{\pi R^{2}}
$$

$P$ represents the strength of adhesion strength, and $F$ is the load value. $R$ is the radius of the diamond indenter.

A dimensional hardness tester (HMV-2T) was used to analyze the hardness of the sample. The loading load was $10 \mathrm{~N}$, and the loading time was $20 \mathrm{~s}$. An atomic force microscope (AFM Dimension Icon), analyzed by NanoScope Analysis software, can be utilized to analyze Young's modulus of the MAO coatings.

\section{RESULTS AND DISCUSSIONS}

\section{Microstructure and Phase Analysis}

Figure 1 shows the XRD pattern of the MAO coatings on AZ91 $\mathrm{Mg}$ alloy prepared at different concentrations of $\mathrm{ZrSiO}_{4}$. Besides the $\mathrm{Mg}$ phase from the substrate, the diffraction peaks of $\mathrm{ZrO}_{2}$, $\mathrm{Mg}_{2} \mathrm{Zr}_{5} \mathrm{O}_{11}, \mathrm{Mg}_{3}\left(\mathrm{PO}_{4}\right)_{2}, \mathrm{MgSiO}_{3}$, and $\mathrm{MgO}$ could be observed, indicating the active involvement of electrolytes in the solution for the MAO process. Specifically, the existence of $\mathrm{ZrO}_{2}$ and $\mathrm{Mg}_{2} \mathrm{Zr}_{5} \mathrm{O}_{11}$ in the coatings also showed the participation of $\mathrm{ZrSiO}_{4}$ decomposed into $\mathrm{ZrO}_{2}$ and $\mathrm{SiO}_{2}$ in the MAO process (Ur Rehman and Choi, 2019). The $\mathrm{SiO}_{2}$ reacted with $\mathrm{MgO}$ to form $\mathrm{MgSiO}_{3}$. Additionally, with the increase in $\mathrm{ZrSiO}_{4}$

TABLE 3 | The parameters obtained from potentiodynamic polarization tests in $3.5 \mathrm{wt} \% \mathrm{NaCl}$.

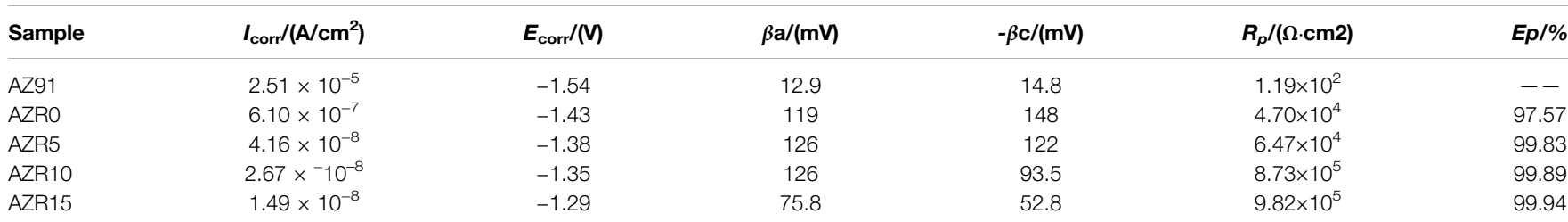




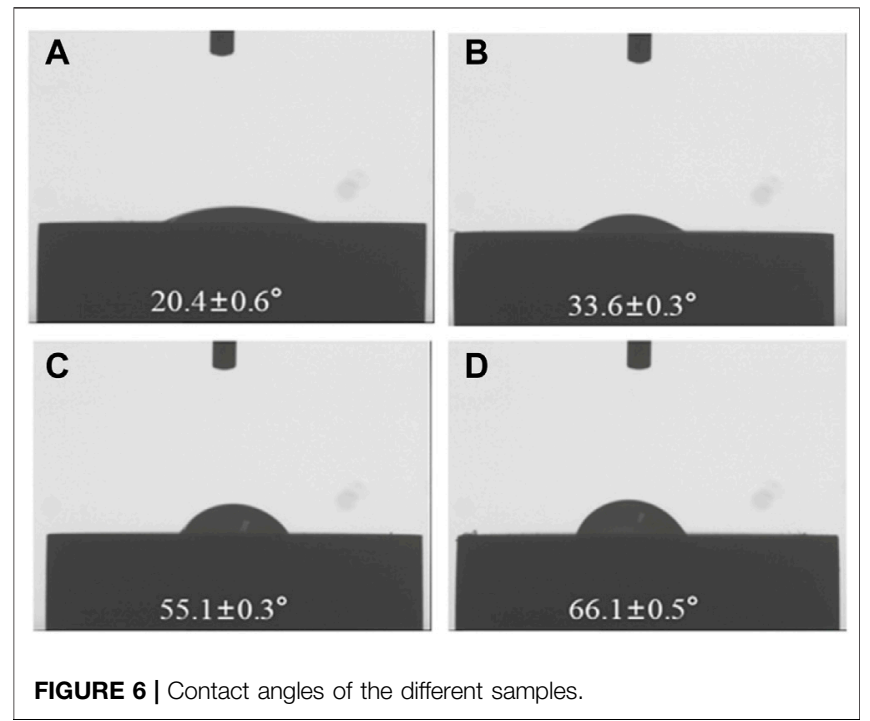

concentration, the peak strength of $\mathrm{ZrO}_{2}$ was also raised gradually (Kovaleva et al., 2021).

Figure 2 represents the surface morphologies of the MAO coatings prepared under preset conditions. All the coatings performed a porous configuration with many crateriform micro-pores unevenly distributed due to the mutual effect of fusional oxides and the gas bubbles in the processes (Xia et al., 2013). As the $\mathrm{ZrSiO}_{4}$ concentrations varied, the surface of samples exhibited a distinct difference. The surfaces of AZR10 and ZAR15 seemed relatively smoother in comparison to AZR0 and ZAR5. The results of the porosity ratio in Figure 3E also illustrated that an increasing $\mathrm{ZrSiO}_{4}$ concentration was simultaneously beneficial to reducing the micro-pores on the surface. These were possibly contributed to the decrease in crateriform pore size and the formation of many blocked pores, combined with more significant amounts of $\mathrm{ZrO}_{2}$ and $\mathrm{SiO}_{2}$ from $\mathrm{ZrSiO}_{4}$ decomposition (Zhang et al., 2020b).

Table 2 shows the contents of each element on the MAO coating surface corresponding to those in Figure 2. It was found that the elements of $\mathrm{O}, \mathrm{Si}, \mathrm{P}, \mathrm{Mg}$, and $\mathrm{Zr}$ were primary in the final MAO coatings. In addition, the contents of $\mathrm{Zr}$ and $\mathrm{Si}$ in AZR15 were higher than those of others, indicating that the content of $\mathrm{ZrSiO}_{4}$ added could directly influence the $\mathrm{Zr}$ and Si contents in the coating, thereby possibly affecting the property of MAO coating.

Figure 4 displays the cross-sectional morphologies and the elemental distribution of different MAO coatings. It shows that all coatings adhered to the $\mathrm{Mg}$ alloy substrate tightly, and there was a relatively dense structure without micropores and large cracks appearing (Gao et al., 2018). Their thickness was also increased clearly with increasing $\mathrm{ZrSiO}_{4}$ content in the electrolyte. In Figures $\mathbf{4} \mathbf{B}, \mathbf{D}, \mathbf{F}, \mathbf{H}$, it could be seen that the elements distributed in the cross section were identical to those on the coating surface. $\mathrm{Zr}$ of the cross-sectional distribution indicated that $\mathrm{ZrSiO}_{4}$ particles were involved in the MAO process.

The variation of film thickness and defects present in coating had a significant impact on the corrosion resistance of the coating to the substrate. Thus, the analysis of corrosion resistance for the coatings was conducted.

\section{Corrosion Resistance}

Figure 5 presents the potentiodynamic polarization curves for the MAO coatings in $3.5 \mathrm{wt} \% \mathrm{NaCl}$ solution. Tafel fitting was also carried out, and the results are listed in Table 3. $\beta_{c}$ represents cathodic hydrogen evolution, and $\beta_{a}$ represents the dissolution of Mg. $E_{\text {corr }}$ and $I_{\text {corr }}$ were the self-etching potential and current density, respectively (Xiong et al., 2018). $R_{p}$ represents polarization resistance. Generally, higher $E_{c o r r}$, lower $I_{c o r r}$, and

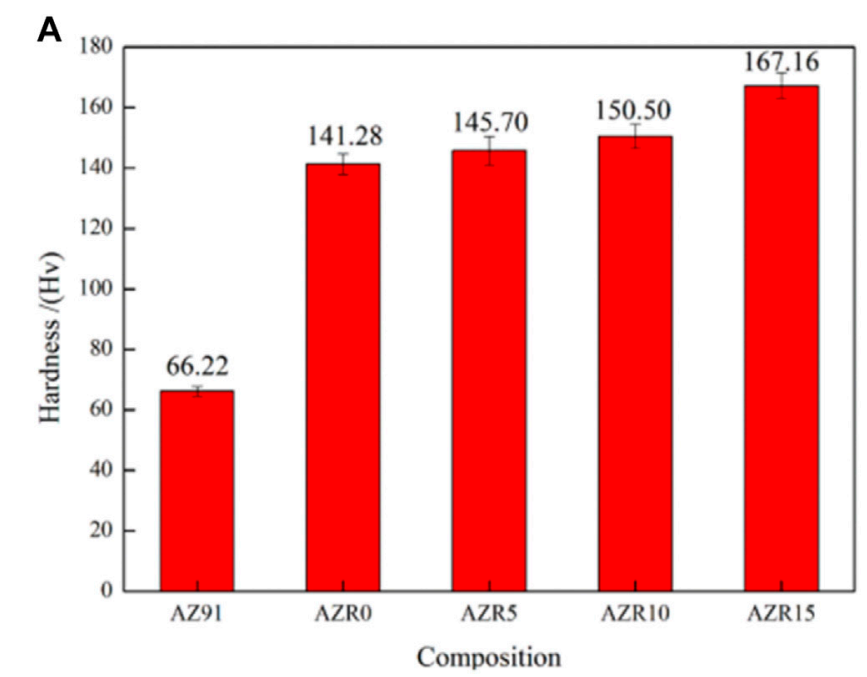

B

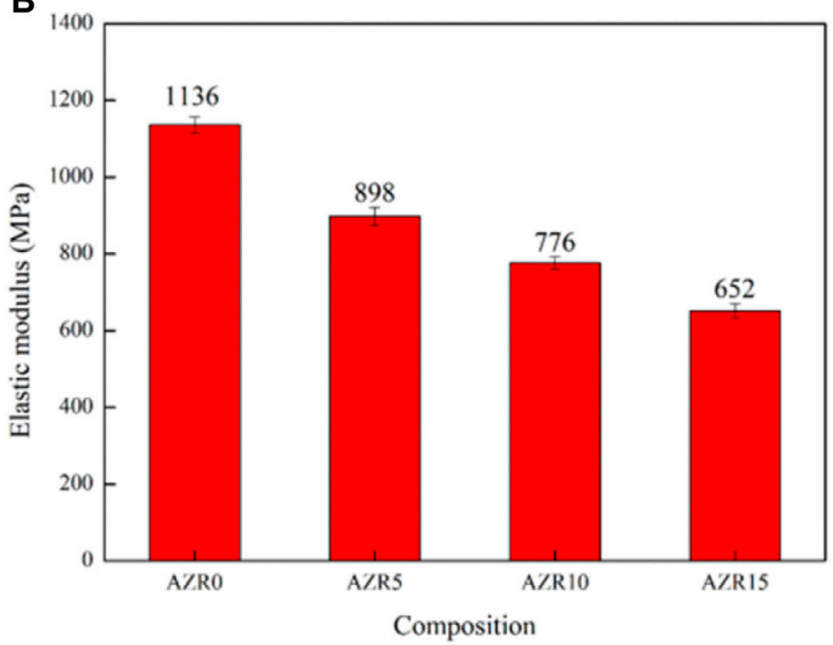

FIGURE 7 | Hardness. (A) Young's modulus and (B) of MAO coating of the different samples. 

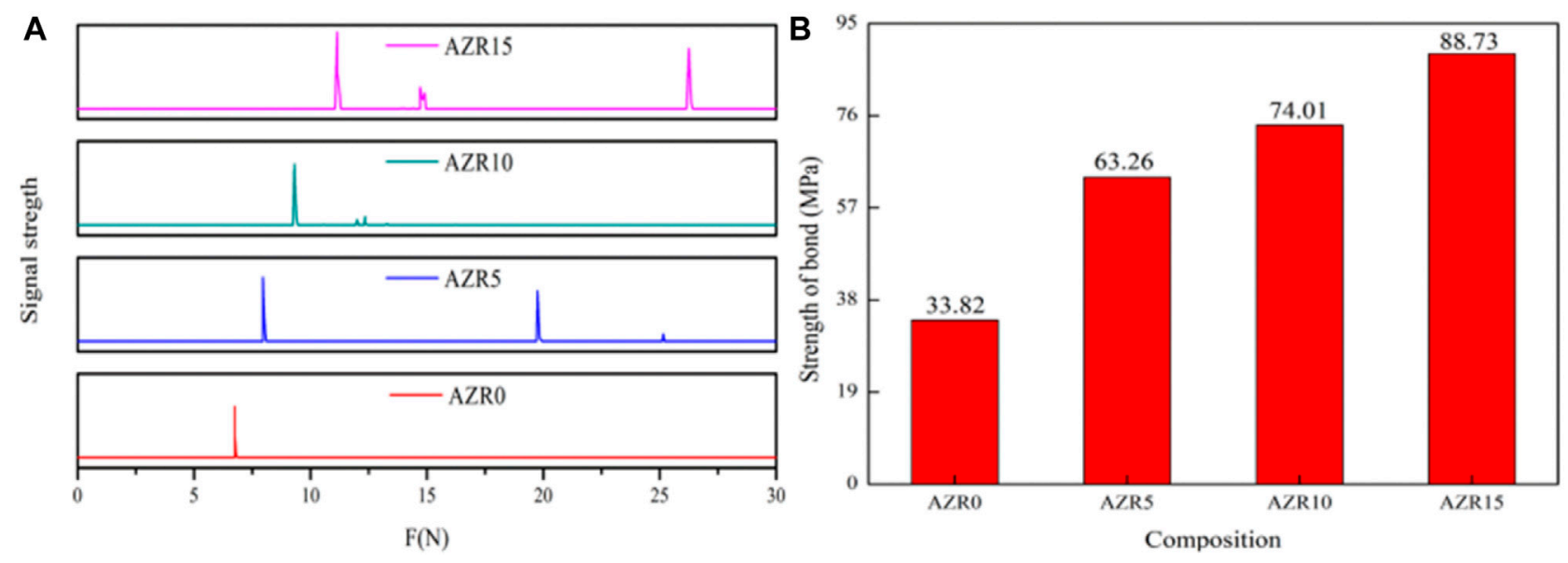

FIGURE 8 | The binding force of the different samples.

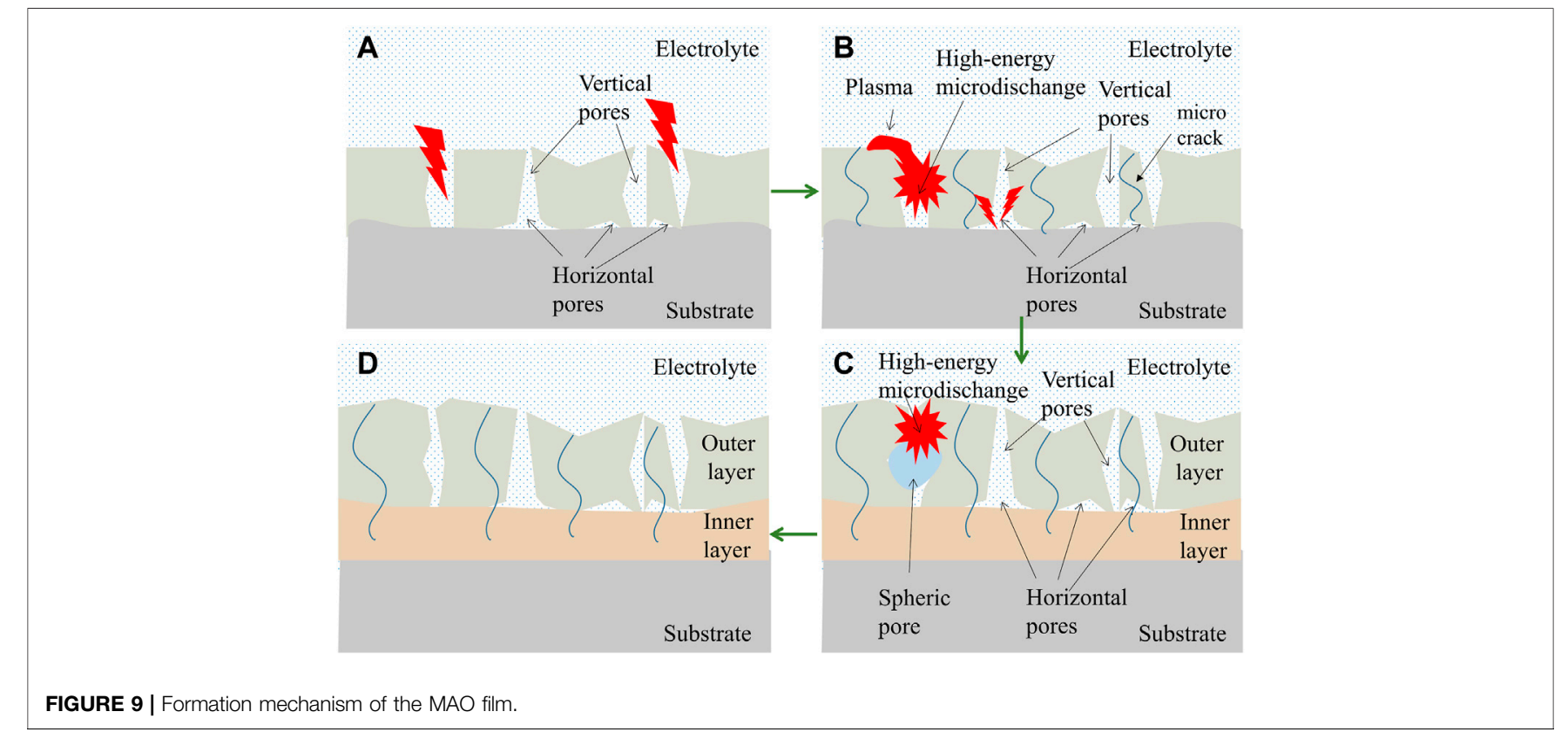

higher $R_{p}$ values implied better anti-corrosion of materials (Wang et al., 2018). It is revealed that adding $\mathrm{ZrSiO}_{4}$ was favorable to increase the $E_{\text {corr }}$ and $R_{p}$ of the coating, and the higher the $\mathrm{ZrSiO}_{4}$ content was, the more significant the improvement of coating anti-corrosion.

Furthermore, the AZR15 specimen, whose $I_{\text {corr }}$ decreased from $2.51 \times 10^{-5}$ for the substrate to $1.49 \times 10^{-8} \mathrm{~A} \mathrm{~cm}^{-2}$, had the best corrosion resistance performance among all samples.

\section{Wettability}

The wettability of the surface also had a significant effect on the corrosion resistance of the coating.

Because of the porous structure of the surface, the MAO coating was susceptible to be hydrophilic (Bordbar-Khiabani et al., 2019). After adding $\mathrm{ZrSiO}_{4}$ to the electrolyte, the contact angle of the coated samples was remarkably and gradually increased. The AZR15 had the highest value of $66.1 \pm 0.5^{\circ}$ in Figure 6. It is revealed that the increase in the $\mathrm{ZrSiO}_{4}$ concentration could significantly enhance the hydrophobicity of the coating surface, thereby preventing the direct contact between corrosive medium and specimen and improving the corrosion resistance of MAO coating. This was consistent with the results of electrochemical tests.

The circulation reaction of corrosive ions $\left(\mathrm{Cl}^{-}\right)$into the film with the substrate was the pre-condition for the corrosion of the $\mathrm{Mg}$ alloy substrate. The inner layer of MAO coating mainly improved the corrosion resistance of the film. According to the above results, there were two main aspects of the improvement of corrosion resistance. Firstly, with the increase in the $\mathrm{ZrSiO}_{4}$ concentration, the hydrophobic surface restrained the entrance 
of corrosive ions $\left(\mathrm{Cl}^{-}\right)$from the surface (Kirkland et al., 2012). Moreover, as seen in Figure 3, the coatings with $\mathrm{ZrSiO}_{4}$ had a low pore density. This behavior could also limit the breakthrough of $\mathrm{Cl}^{-}$to the coating/substrate boundary. Moreover, the thickness rise of the coating further enhanced the paths for the corrosive ions through the coating, thus increasing the anticorrosion of MAO coating.

\section{Mechanical Properties}

Figure 7 exhibits the change of the hardness 1) and Young's modulus 2) at the different samples. Owing to the increasing concentration of $\mathrm{ZrSiO}_{4}$ in the coatings, the samples' hardness was also increased. AZR15 had the highest value of $167.16 \mathrm{Hv}$ (Zuo et al., 2019). Meanwhile, Young's modulus of the samples was lower than that of pure AZ91 alloy $(1136 \mathrm{MPa})$, and this value of AZR15 was decreased to $652 \mathrm{MPa}$. Its mechanical strength depended on porosity, which depended on its manufacturing process (Es-saddik et al., 2021). During the MAO process, $\mathrm{ZrSiO}_{4}$ particles could separate into $\mathrm{ZrO}_{2}$, thereby reducing the micro-cracks and other defects in the film and affecting the mechanical properties of the samples.

\section{Adhesion Strength}

Figure 8 shows the binding strength of the coatings for the specimens. It can be seen that the binding strength of AZR0 and AZR15 films were 33.82 and $88.73 \mathrm{MPa}$, respectively, indicating the significant effect of $\mathrm{ZrSiO}_{4}$ on enhancing the binding strength between coating and substrate. The $\mathrm{ZrSiO}_{4}$ dispersed in the electrolyte could enter the discharge channel of forming coating during the MAO process. Its decomposition $\mathrm{ZrO}_{2}$ could be as particles present in the cooling and solidifying coating process, which may be improved compactness and restrain the crack propagation of formed MAO coating, resulting in higher binding force and lower Young's modulus (Yao et al., 2019).

\section{Formation Mechanism of the Coating}

Figure 9 shows formation mechanism of MAO film. The forming process of the composite coating was presented as follows: during the MAO process, the high voltage generated an electric domain between the cathode and anode attended by the constitution of micro discharge exiting on the $\mathrm{Mg}$ alloy substrate. The micro discharges burning under the loose coating layer caused the oxidation of the $\mathrm{Mg}$ alloy substrate, but the oxides were not carried to the surface of the loosened coating. During this stage, two micro discharges (blunt little micro-discharges and transparently burning ones) occurred on the coating surface. Then in the next stage, there was a higher possibility of blocking the pores above the dense coating layer or these pores moving from the substrate to the interface of inner/outer layers. This is the result in regional sealing of the pores when inner micro discharges were ignited. Micro discharges with weak stress could be observed (high-energy micro discharges blank) on the surfaces. At this stage, sealing of the pores in the coating of AZ91 was dominated (Rakoch et al., 2020).

The phase composition was formed by the different reactions during the MAO process (Baghdadabad et al., 2020; Kovaleva et al., 2021).

$$
\begin{aligned}
\mathrm{Mg} & =\mathrm{Mg}^{2+}+2 \mathrm{e}^{-} \\
\mathrm{Mg}^{2+}+\mathrm{O}^{2-} & =\mathrm{MgO} \\
3 \mathrm{Mg}^{2+}+2 \mathrm{PO}_{4}^{3-} & =\mathrm{Mg}_{3}\left(\mathrm{PO}_{4}\right)_{2} \\
\mathrm{ZrSiO}_{4} & =\mathrm{ZrO}_{2}+\mathrm{SiO}_{2} \\
2 \mathrm{Mg}^{2+}+\mathrm{SiO}_{3}^{2-}+2 \mathrm{OH}^{-} & =\mathrm{Mg}_{2} \mathrm{SiO}_{4}+\mathrm{H}_{2} \mathrm{O} \\
\mathrm{Mg}_{2} \mathrm{SiO}_{4}+\mathrm{SiO}_{2} & \left.=\mathrm{MgSiO}_{3} \text { (Heat }\right) \\
\mathrm{Mg}^{2+}+\mathrm{SiO}_{3}^{2-} & =\mathrm{MgSiO}_{3} \\
\mathrm{MgO}+\mathrm{SiO}_{2} & =\mathrm{MgSiO}_{3} \\
2 \mathrm{MgO}+5 \mathrm{ZrO}_{2} & =\mathrm{Mg}_{2} \mathrm{Zr}_{5} \mathrm{O}_{11}
\end{aligned}
$$

\section{CONCLUSION}

In this work, $\mathrm{MAO}$ coatings were successfully prepared on the AZ91 $\mathrm{Mg}$ alloy in $\mathrm{Na}_{2} \mathrm{SiO}_{3}-\mathrm{Na}_{3} \mathrm{PO}_{4}$ based solution with various $\mathrm{ZrSiO}_{4}$ concentrations. The results of the present investigation were as the following:

1. $\mathrm{ZrO}_{2}$ and $\mathrm{SiO}_{2}$ are produced by $\mathrm{ZrSiO}_{4}$ particles and participate in the process into the MAO layer. With $\mathrm{ZrSiO}_{4}$ particles concentration increasing, the MAO coatings became denser, and the holes in the coating significantly decreased. The micro-cracks and defects were also reduced on the surface of the coating.

2. The corrosion resistance and mechanical properties were significantly improved when $\mathrm{ZrSiO}_{4}$ was added to the electrolyte. Meanwhile, the best performance in aspects of self-corrosion potential $(-1.289 \mathrm{~V})$, self-corrosion current $\left(1.49 \times 10^{-8} \mathrm{~A} \mathrm{~cm}^{2}\right)$, polarization resistance $(9.82 \times$ $10^{5} \Omega \cdot \mathrm{cm} 2$ ), and protection efficiency $(99.94 \%)$ were found in the $\mathrm{ZrSiO}_{4}$ concentration of $15 \mathrm{~g} / \mathrm{l}$. In addition, the $\mathrm{ZrSiO}_{4}$ concentration also enhanced the hardness and decreased Young's modulus of the coatings.

\section{DATA AVAILABILITY STATEMENT}

The raw data supporting the conclusion of this article will be made available by the authors, without undue reservation.

\section{AUTHOR CONTRIBUTIONS}

TL: writing-original draft, formal analysis. GC: methodology, visualization. MX: formal analysis. YZ: writing-review and editing, supervision. MC: writing-review and editing, supervision, project administration.

\section{ACKNOWLEDGMENTS}

The authors acknowledge the financial support for this work from the Key projects of the Joint Foundation of the National Natural Science Foundation of China (U1764254), and National Nature Science Foundation of China (51871166 and 51801137). 


\section{REFERENCES}

Arrabal, R., Matykina, E., Skeldon, P., and Thompson, G. E. (2008). Incorporation of Zirconia Particles into Coatings Formed on Magnesium by Plasma Electrolytic Oxidation. J. Mater. Sci. 43, 1532-1538. doi:10.1007/s10853-007-2360-9

Baghdadabad, D. M., Baghdadabad, A. R. M., and Khoei, S. M. M. (2020). Characterization of Bioactive Ceramic Coatings Synthesized by Plasma Electrolyte Oxidation on AZ31 Magnesium alloy Having Different Na2SiO3 Center Dot 9H(2)O Concentrations. Mater. Today Commun. 25, 101642. doi:10.1016/ j.mtcomm.2020.101642

Bordbar-Khiabani, A., Yarmand, B., and Mozafari, M. (2019). Enhanced Corrosion Resistance and In-Vitro Biodegradation of Plasma Electrolytic Oxidation Coatings Prepared on AZ91 Mg alloy Using ZnO NanoparticlesIncorporated Electrolyte [J]. Surf. Coat. Technol. 360, 153-171. doi:10.1016/j.surfcoat.2019.01.002

Cao, Y., Ning, X., and Wang, Q. (2021). Compositional Control and HighTemperature Phase Stability of Plasma-Sprayed $\mathrm{Ba}(\mathrm{Mgu}(1 / 3) \mathrm{Ta}(2 / 3)) \mathrm{O}-3$ Coatings. Surf. Coat. Technol. 425, 127714. doi:10.1016/ j.surfcoat.2021.127714

Es-saddik, M., Laasri, S., Taha, M., Laghzizil, A., Guidara, A., Chaari, K., et al. (2021). Effect of the Surface Chemistry on the Stability and Mechanical Properties of the Zirconia-Hydroxyapatite Bioceramic. Surf. Inter. 23, 100980. doi:10.1016/j.surfin.2021.100980

Fattah-alhosseini, A., Chaharmahali, R., and Babaei, K. (2020). Effect of Particles Addition to Solution of Plasma Electrolytic Oxidation (PEO) on the Properties of PEO Coatings Formed on Magnesium and its Alloys: A Review. J. Magnesium Alloys 8, 799-818. doi:10.1016/ j.jma.2020.05.001

Gao, G., Li, Y., Hu, D., and Xi, Z. (2018). Structure and Infrared Emissivity Properties of the MAO Coatings Formed on TC4 Alloys in K2ZrF6-Based Solution. Materials 11, 254. doi:10.3390/ma11020254

Kirkland, N. T., Schiller, T., and Medhekar, N. (2012). Exploring Graphene as a Corrosion protection Barrier. Corrosion Sci. 56, 1-4. doi:10.1016/ j.corsci.2011.12.003

Kovaleva, E., Kusiak, M. A., Kenny, G. G., Whitehouse, M. J., Habler, G., Schreiber, A., et al. (2021). Nano-Scale Investigation of Granular Neoblastic Zircon, Vredefort Impact Structure, South Africa: Evidence for Complete Shock Melting. Earth Planet. Sci. Lett. 565, 116948. doi:10.1016/j.epsl.2021.116948

Li, C.-Y., Fan, X.-L., Cui, L.-Y., and Zeng, R.-C. (2020). Corrosion Resistance and Electrical Conductivity of a Nano ATO-Doped MAO/Methyltrimethoxysilane Composite Coating on Magnesium alloy AZ31. Corrosion Sci. 168, 108570. doi:10.1016/j.corsci.2020.108570

Li, C.-Y., Yu, C., Zeng, R.-C., Zhang, B.-C., Cui, L.-Y., Wan, J., et al. (2020). In Vitro corrosion Resistance of a Ta2O5 Nanofilm on MAO Coated Magnesium alloy AZ31 by Atomic Layer Deposition. Bioactive Mater. 5, 34-43. doi:10.1016/j.bioactmat.2019.12.001

Li, H., Sun, Y., and Zhang, J. (2015). Effect of ZrO2 Particle on the Performance of Micro-arc Oxidation Coatings on Ti6Al4V. Appl. Surf. Sci. 342, 183-190. doi:10.1016/j.apsusc.2015.03.051

Li, T., Li, L., Qi, J., and Chen, F. (2020). Corrosion protection of Ti6Al4V by a Composite Coating with a Plasma Electrolytic Oxidation Layer and Sol-Gel Layer Filled with Graphene Oxide. Prog. Org. Coat. 144, 105632. doi:10.1016/ j.porgcoat.2020.105632

Li, Z., He, Z., Lai, H., He, Y., Zhu, Z., Chen, Y., et al. (2021). One-Step Synthesis of Oxygen-Defects Modified Ta2O5 Nanosheets with High Photocatalytic Performance by Chemical Vapor Deposition Method. Appl. Surf. Sci. 567, 150776. doi:10.1016/j.apsusc.2021.150776

Lim, T. S., Ryu, H. S., and Hong, S.-H. (2012). Electrochemical Corrosion Properties of $\mathrm{CeO} 2-$ Containing Coatings on AZ31 Magnesium Alloys Prepared by Plasma Electrolytic Oxidation. Corrosion Sci. 62, 104-111. doi:10.1016/j.corsci.2012.04.043

Lu, X., Mohedano, M., Blawert, C., Matykina, E., Arrabal, R., Kainer, K. U., et al. (2016). Plasma Electrolytic Oxidation Coatings with Particle
Additions - A Review. Surf. Coat. Technol. 307, 1165-1182. doi:10.1016/j.surfcoat.2016.08.055

Rahman, M., Li, Y., and Wen, C. (2020). Realization and Characterization of Double-Layer Ca-P Coating on WE43 Mg alloy for Biomedical Applications. Surf. Coat. Technol. 398, 126091. doi:10.1016/ j.surfcoat.2020.126091

Rakoch, A. G., Monakhova, E. P., Khabibullina, Z. V., Serdechnova, M., Blawert, C., Zheludkevich, M. L., et al. (2020). Plasma Electrolytic Oxidation of AZ31 and AZ91 Magnesium Alloys: Comparison of Coatings Formation Mechanism. J. Magnesium Alloys 8, 587-600. doi:10.1016/j.jma.2020.06.002

Rehman, Z. U., Shin, S. H., Hussain, I., and Koo, B. H. (2017). Investigation of Hybrid PEO Coatings on AZ31B Magnesium alloy in Alkaline K2ZrF6Na2SiO3 Electrolyte Solution. Prot. Met. Phys. Chem. Surf. 53, 495-502. doi:10.1134/s2070205117030194

Ur Rehman, Z., and Choi, D. (2019). Investigation of ZrO2 Nanoparticles Concentration and Processing Time Effect on the Localized PEO Coatings Formed on AZ91 alloy. J. Magnesium Alloys 7, 555-565. doi:10.1016/j.jma.2019.10.001

Wang, S.-Y., Si, N.-C., Xia, Y.-P., and Liu, L. (2015). Influence of Nano-SiC on Microstructure and Property of MAO Coating Formed on AZ91D Magnesium alloy. Trans. Nonferrous Met. Soc. China 25, 1926-1934. doi:10.1016/s1003-6326(15)63800-6

Wang, Y., Zhang, S., Lu, Z., Wang, L., and Li, W. (2018). Preparation and Performances of Electrically Conductive Nb-Doped $\mathrm{TiO} 2$ Coatings for 316 Stainless Steel Bipolar Plates of Proton-Exchange Membrane Fuel Cells. Corrosion Sci. 142, 249-257. doi:10.1016/ j.corsci.2018.07.034

Xia, Y. H., Zhang, B. P., Lu, C. X., and Geng, L. (2013). Improving the Corrosion Resistance of $\mathrm{Mg}-4.0 \mathrm{Zn}-0.2 \mathrm{Ca}$ alloy by Micro-arc Oxidation. Mater. Sci. Eng. C 33, 5044-5050. doi:10.1016/ j.msec.2013.08.033

Xiong, C., Li, W., Jin, Z., Gao, X., Wang, W., Tian, H., et al. (2018). Preparation of Phytic Acid Conversion Coating and Corrosion protection Performances for Steel in Chlorinated Simulated concrete Pore Solution. Corrosion Sci. 139, 275-288. doi:10.1016/ j.corsci.2018.05.018

Yang, Q., Li, P., and Zhang, S. (2021). Low Temperature Synthesis of green Submicro $\mathrm{Cr}-\mathrm{ZrSiO} 4$ Ceramic Pigments by Solid-State Method. Int. J. Appl. Ceram. Technol. 18, 345-352. doi:10.1111/ ijac. 13648

Yao, J., Wang, Y., Wu, G., Sun, M., Wang, M., and Zhang, Q. (2019). Growth Characteristics and Properties of Micro-arc Oxidation Coating on SLMProduced TC4 alloy for Biomedical Applications. Appl. Surf. Sci. 479, 727-737. doi:10.1016/j.apsusc.2019.02.142

Zarei, M., Nourouzi, S., Jamaati, R., Cano, I. G., Dosta, S., and Sarret, M. (2021). Water-Assisted Crystallization of Nanoporous Tin Oxide Formed by Anodic Oxidation on Cold Sprayed Tin Coating. J. Alloys. Compd. 876, 160207. doi:10.1016/ j.jallcom.2021.160207

Zhang, X.-M., Chen, D.-F., Gong, C.-Z., Yang, S.-Q., and Tian, X.-B. (2010). Modulation Effects of K2ZrF6 Additive on Microstructure and Heat Resistance of Micro-arc Oxide Coatings Fabricated on LY12 Alumi-Num Alloy. J. Inorg. Mater. 25, 865-870. doi:10.3724/ sp.j.1077.2010.00865

Zhang, Y., Chen, F., Zhang, Y., and Du, C. (2020). Influence of Graphene Oxide Additive on the Tribological and Electrochemical Corrosion Properties of a PEO Coating Prepared on AZ31 Magnesium alloy. Tribology Int. 146, 106135. doi:10.1016/ j.triboint.2019.106135

Zhang, Y., Chen, F., Zhang, Y., Liu, Z., Wang, X., and Du, C. (2019). Influence of Graphene Oxide on the Antiwear and Antifriction Performance of MAO Coating Fabricated on Mg Li alloy. Surf. Coat. Technol. 364, 144-156. doi:10.1016/j.surfcoat.2019.01.103

Zhang, Y., Sil, M. C., and Chen, C. (2021). Organosiloxane Nanolayer as Diffusion Barrier for Cu Metallization on Si. Appl. Surf. Sci. 567, 150800. doi:10.1016/ j.apsusc.2021.150800 
Zhang, Z.-Q., Wang, L., Zeng, M.-Q., Zeng, R.-C., Kannan, M. B., Lin, C.-G., et al. (2020). Biodegradation Behavior of Micro-arc Oxidation Coating on Magnesium alloy-from a Protein Perspective. Bioactive Mater. 5, 398-409. doi:10.1016/j.bioactmat.2020.03.005

Zhou, K., Xie, F., Wu, X., and Wang, S. (2021). Fretting Wear Behavior of Nano ZrO2 Doped Plasma Electrolytic Oxidation Composite Coatings on TC21 Titanium alloy. Surf. Coat. Technol. 421, 127429. doi:10.1016/j.surfcoat.2021.127429

Zuo, Y., Li, T., Yu, P., Zhao, Z., Chen, X., Zhang, Y., et al. (2019). Effect of Graphene Oxide Additive on Tribocorrosion Behavior of MAO Coatings Prepared on Ti6Al4V alloy. Appl. Surf. Sci. 480, 26-34. doi:10.1016/j.apsusc.2019.02.065

Conflict of Interest: The authors declare that the research was conducted in the absence of any commercial or financial relationships that could be construed as a potential conflict of interest.
Publisher's Note: All claims expressed in this article are solely those of the authors and do not necessarily represent those of their affiliated organizations, or those of the publisher, the editors, and the reviewers. Any product that may be evaluated in this article, or claim that may be made by its manufacturer, is not guaranteed or endorsed by the publisher.

Copyright (c) $2022 \mathrm{Li}$, Chen, Xiang, Zhao and Chen. This is an open-access article distributed under the terms of the Creative Commons Attribution License (CC BY). The use, distribution or reproduction in other forums is permitted, provided the original author(s) and the copyright owner(s) are credited and that the original publication in this journal is cited, in accordance with accepted academic practice. No use, distribution or reproduction is permitted which does not comply with these terms. 